\title{
Dehydrator Onion Bulb Weight and Water-soluble Carbohydrates before and after Maturity
}

\author{
Arthur D. Wall, ${ }^{1}$ Marisa M. Wall, ${ }^{2}$ and Joe N. Corgan ${ }^{3}$ \\ Department of Agronomy and Horticulture, Box 30003, MSC 3Q, New Mexico State University, Las Cruces, \\ $N M, 88003$
}

\begin{abstract}
AdDitional INDEX wORDs. Allium cepa L., nonstructural carbohydrates, soluble solids, fructans, sugars, bulb mass, bulb size, high performance liquid chromatography

Abstract. Onions (Allium cepa $\mathrm{L}$.) with $\geq \mathbf{1 8 \%}$ bulb dry weight are dehydrated and used for spices and food ingredients. Bulb weight characteristics and water-soluble carbohydrates (WSC) of two commercial dehydrator cultivars, GS02 and GS04, and a breeding population, NM9335, were studied before and after maturity to observe phenotypic traits that may be useful for selection during breeding programs, and to study dehydrator onion carbohydrate physiology. At maturity, NM9335, GS02, and GS04 bulbs had 11.9 $\pm 0.33 \%, 18.6 \pm 0.27 \%$, and $19.4 \pm 0.40 \%$ dry weight, respectively. Mature GS04 plants had $76.5 \pm 0.01 \%$ of whole plant dry weight in bulbs, which is an extraordinarily high crop harvest index. NM9335 bulbs had higher fresh (hydrated) weight than bulbs of GS04 and GS02, but bulbs in all populations accumulated similar amounts of dry weight. Bulb percent dry weight before maturity did not indicate percent dry weight at maturity in the high-solids commercial onion cultivars. Bulb percent dry weight declined slightly after maturity in all populations. Glucose, fructose, and sucrose were relatively low, and fructans with degree of polymerization $\geq 6$ were relatively high in GS04, but the converse was observed in NM9335. Relative amounts of GSO4 bulb fructan increased sequentially, in order of rank, from DP4 to DP6, but the converse was observed for NM9335.
\end{abstract}

White-skinned onion cultivars are dehydrated and used as primary ingredients in food seasonings and spices (American Spice Trade Association, 1993; Fenwick and Hanley, 1990). Dehydrator onion cultivars with $\geq 18 \%$ bulb dry weight (solids) content are distinct from fresh market types, with $\approx 5 \%$ to $9 \%$ bulb solids, and storage types, with $\approx 8 \%$ to $12 \%$ bulb solids (Darbyshire and Steer, 1990). Onion solids increase from inner to outer scales, and from the base to the apex of onion bulbs and plants (Darbyshire and Henry, 1978). Onion water soluble carbohydrate (WSC), or nonstructural carbohydrate, forms $80 \%$ to $87 \%$ of bulb dry weight, and is comprised of glucose, fructose, sucrose, and fructans. Onion fructans are fructose polysaccharides (oligosaccharides), with degree of polymerization (DP) from 3 to 15 subunits, depending on population (Darbyshire and Henry, 1979; Darbyshire and Steer, 1990; Suzuki and Cutcliffe, 1989). Other Allium species can accumulate fructans with DP > 15 (Darbyshire and Henry, 1981). The most basic fructans are DP3 trisaccharides, synthesized by transfer of a fructose molecule to sucrose, to form two isomers: $1^{\mathrm{F}}$-fructosylsucrose and $6^{\mathrm{G}}$-fructosylsucrose. Longer DP fructans form by addition of fructose subunits to $\geq D P 3$ fructan (Endleman and Jefford, 1968; Henry and Darbyshire, 1979). However, Cairns (1993) states that previous reports on fructan synthesis require reappraisal, and that fructan synthesis enzyme chemistry is still poorly understood.

Onion dry weight content is usually measured indirectly by using a refractometer to assay for soluble solids content (SSC) in onion juice (Dowker, 1990; Pike, 1986). Sinclair et al. (1995) report a 0.99 correlation between refractometer SSC readings and actual dry

Received for publication 17 Sept. 1998. Accepted for publication 17 Aug. 1999. We thank Cindy Waddell for support in the HPLC analysis, Jose Luis Mendoza, Helen Redden, Melodie Borden, and M.R. Doyle for research assistance, and Gilroy Foods, Inc. for providing commercial dehydrator onion seed used in this study. The research was supported by the New Mexico Agricultural Experiment Station, The New Mexico Dry Onion Commission, and the Jose Fernandez Chair for Crop Production. The cost of publishing this paper was defrayed in part by the payment of page charges. Under postal regulations, this paper therefore must be hereby marked advertisement solely to indicate this fact.

${ }^{1}$ Graduate research assistant.

${ }^{2}$ Associate professor.

${ }^{3}$ Professor emeritus and Jose Fernandez chair for crop production. weight content in a study of 49 diverse onion cultivars. Several other studies also have proven that SSC is an effective selection criterion for dry weight content (Mann and Hoyle, 1945; Nieuwhof et al., 1973). Bulb SSC directly indicates dry weight content, but does not indicate profiles of constituent WSC. Nondestructive gravimetric methods and near-infrared spectrophotometry also can be used to test for SSC or dry weight in onions (Birth and Dull, 1985; Kehr, 1952).

The present work was conducted to characterize the accumulation of dehydrator onion bulb fresh and dry weight before maturity, and the retention of bulb fresh and dry weight after maturity, by onion populations differing in dry matter percentage (SSC). Postmaturity treatments were included to study these traits in onions during periods when harvest was delayed past maturity, and during summer bulb dormancy. Ratios and proportions (profiles) of constituent WSC were determined in a commercial cultivar and a breeding population before and after maturity using high-performance liquid chromatography (HPLC), to gain a better understanding of WSC metabolism in dehydrator onion bulbs. The relative differences in WSC profiles over various maturities may serve as phenotypic markers for onion breeding and physiology research. The contribution of leaves and pseudostem to dry matter partitioning was studied in a high solids onion cultivar to observe weight accumulation and translocation during the bulb-fill period. Previous research has described onion bulb weight characteristics and WSC at maturity in cultivars that differin dry matter percentage(Darbyshire and Henry, 1978, 1979; Darbyshire and Steer, 1990). However, presently there are no reports on dehydrator onion bulb carbohydrate and dry matter accumulation before maturity, or retention in bulbs that remain rooted in situ after maturity. Additionally, the HPLC method used in this study is a new modified procedure that provides relatively efficient qualitative analysis of onion WSC, which could be especially useful for onion breeding and processing quality control programs.

\section{Materials and Methods}

Populations. Two intermediate-day dehydrator onion cultivars 'GS02' and 'GS04', and an intermediate-day open-pollinated N.M. 
State Univ. breeding line, 'NM9335', were chosen for this study. The GS02 and GS04 cultivars are proprietary cultivars that are used in commercial dehydrator onion production in California. The NM9335 dehydrator onion breeding population was an openpollinated $\mathrm{F}_{7}$ generation that originated from the cross of 'Ben Shemen' x 'Southport White Globe' and had one previous selection cycle for SSC. The NM9335 population was well adapted to the experimental location, which was indicated by vigorous growth, large bulbs, and disease resistance. The GS02 and GS04 cultivars had relatively small bulbs that had more symptoms of pink root (Phoma terrestris Hansen) and fusarium basal rot [Fusarium oxysporum f. sp. cepae (Hans) Snyder and Hansen], relative to NM9335.

FieLD EXPERIMENTS. Experiments were conducted in 1994 and 1995, and were located at the Fabian Garcia Agricultural Science Center in Las Cruces, N.M. A split-plot experimental design with six replications was used for bulb characteristic studies before and after maturity. Onion populations were planted in rows to form main plots, and maturity treatments were applied as subplots within rows. A randomized complete block design with six replications was used for plant-weight partitioning studies of the GS04 cultivar. Plots were established $1.1 \mathrm{~m}$ long, with a $1-\mathrm{m}$ row spacing, and with four equally spaced lines of plants direct-seeded in a 76-cm-wide bed on 26 Jan., both years. Seedlings were hand thinned to $6 \mathrm{~cm}$ between plants at four weeks after emergence. The crop was managed according to standard practices for southern New Mexico, with water and nitrogen applied using drip irrigation (Bailey and Corgan, 1986; Corgan and Kedar, 1990). Plots were considered mature when $\approx 80 \%$ of the tops had fallen. Predicted and actual maturity closely coincided both years. The NM9335 population matured on 15 July 1994 and 10 July 1995. The GS02 cultivar matured on 13 July 1994 and on 7 July 1995, and the GS04 cultivar matured on 7 July 1994 and on 20 July 1995. Onion bulbs were hand harvested from within the middle $0.9 \mathrm{~m}$ of the plot. Onion roots and tops were clipped at harvest, diseased bulbs were discarded, and harvested bulbs were stored temporarily in paper bags at ambient air temperature $(\approx 25$ ${ }^{\circ} \mathrm{C}$ ). Bulbs were left rooted in place with tops attached, for postmaturity harvest treatments. During 1994, treatments were designed to harvest plots at 45,30 , and 15 d before maturity, at maturity, and at 15,30 , and $45 \mathrm{~d}$ after maturity. The $45 \mathrm{~d}$ treatments were omitted from the 1995 experiments.

On the day of harvest, and just before testing, bulbs were washed and dried to remove soil and dry scales, top and root stubble were removed, and fresh yield data was obtained from these samples. Samples of GS04 plants were prepared for weight partitioning studies by cutting 10 plants from each replication into leaves, pseudostems, and bulbs. Percent dry weight was determined by hand chopping the 10-bulb subsample and the plant parts into coarse pieces $(\approx 2$ to $3 \mathrm{~cm})$, which were then dried at $100^{\circ} \mathrm{C}$ for $1 \mathrm{~h}$, and then at 70 to $75^{\circ} \mathrm{C}$ for $48 \mathrm{~h}$, in a forced air convection oven. Dried samples were frozen at $-10^{\circ} \mathrm{C}$ subsequent to WSC analysis using HPLC. Average bulb fresh weight was calculated by dividing plot fresh yield by the number of bulbs per plots. Average bulb dry weight was calculated by multiplying average bulb fresh weight by average bulb percent dry weight.

WATER-SOLUBLE CARBOHYDRATE ANALYSIS. HPLC analysis was conducted according to the modified methods of Suzuki and Cutcliffe (1989) and Scobell et al. (1977), and four replications of each field treatment were analyzed. Dried bulb samples were further prepared by chopping and mixing in a food processor, and then 20 to $30 \mathrm{~g}$ of these flakes were ground into powder to pass through an 80 mesh screen. Powder was mixed with triple distilled water $(1 \mathrm{~g} / 100 \mathrm{~mL})$ and shaken for $1 \mathrm{~h}$ at $25^{\circ} \mathrm{C}$. Solutions were vacuum filtered through \#40 filter paper, and then refiltered into HPLC vials through a $45 \mu \mathrm{m}$ membrane filter disc. The vials were sealed and then immediately stored at $-10{ }^{\circ} \mathrm{C}$ before HPLC analysis.

Carbohydrates were analyzed by injecting $20 \mu \mathrm{L}$ of sample solution into a Hewlett-Packard 1090 series liquid chromatograph with deionized, distilled, degassed water as the mobile phase, and an ion moderated partition column (Bio-Rad Aminex HPX-42A, Hercules, Calif.) as the stationary phase, followed by a Hewlett Packard 1047A refractive index detector. A flow rate of $0.6 \mathrm{~mL} \cdot \mathrm{min}^{-1}$ and a column temperature of $85^{\circ} \mathrm{C}$ were used.

Glucose, fructose, and sucrose standard sugars were used to calculate column retention times for these onion WSC. Highfructose corn syrup oligosaccharide standards indicated the column was detecting polysaccharides in sequential rank of degree of polymerization (DP), which infers that onion fructans also elute in sequential rank of DP. Quantitative analysis of onion WSC was not possible because fructan standards were not available. Previous research on onion WSC confirms that glucose, fructose, sucrose and fructans are the only constituent WSC carbohydrates found in Allium cepa $\mathrm{L}$., and that fructans elute in sequence, based on rank of fructan DP (Darbyshire and Henry, 1978, 1979). Based on these assumptions, relative amounts of WSC were estimated from peak
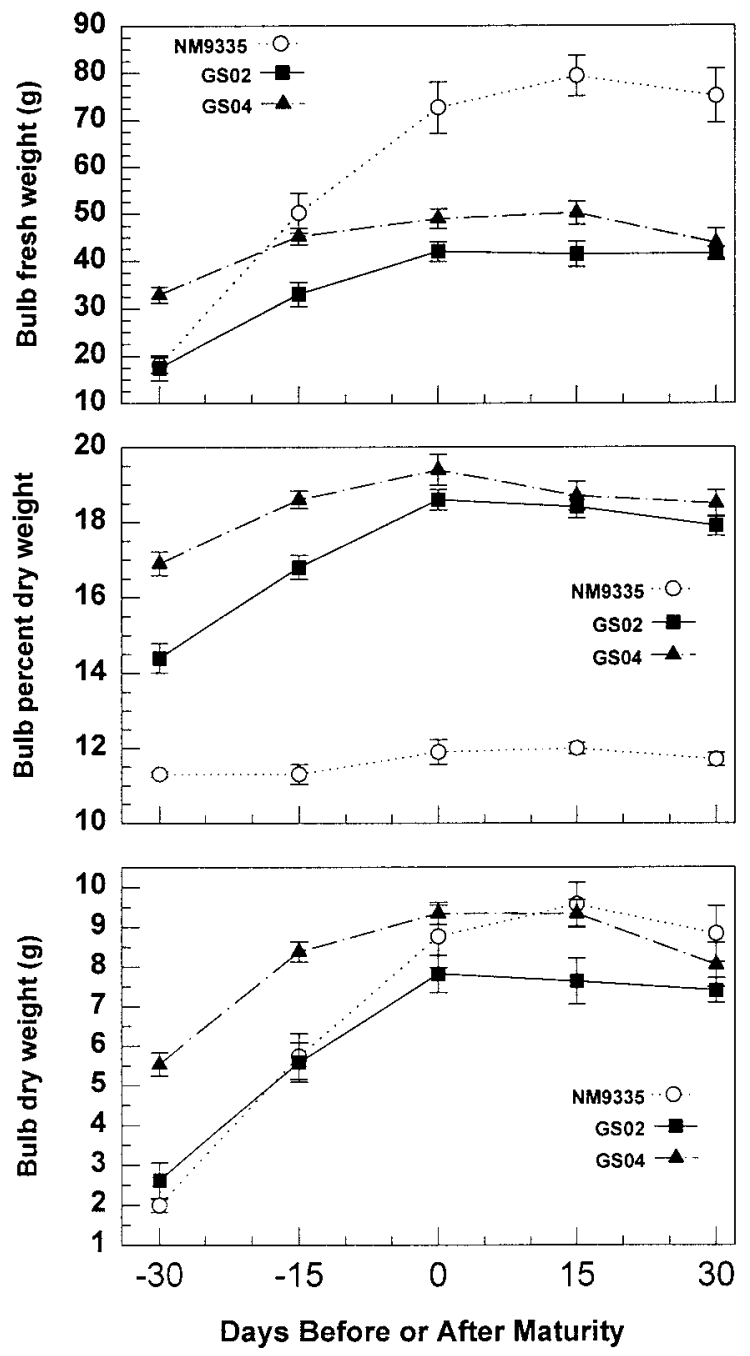

Fig. 1. Bulb weight characteristics of three dehydrator onion populations before and after maturity, averaged over 1994 and 1995. 
areas of chromatograms, and WSC identification was based on column retention time.

\section{Results and Discussion}

Analysis of variance and homogeneity of variance tests indicated that data should be combined and averaged for 1994 and 1995.

BULB WEIGHT CHARACTERISTICS BEFORE AND AFTER MATURITY. NM9335 bulbs accumulated fresh weight at a faster rate before maturity than bulbs of GS02 and GS04. NM9335 bulb fresh weight was much higher than GS04 and GS02 bulbs at maturity. However, because NM9335 had lower bulb percent dry weight than GS02 or GS04, all populations accumulated similar amounts of bulb dry weight (Fig. 1). Bulb fresh weight remained about the same after maturity for each population, although bulbs of GS04 lost fresh weight $30 \mathrm{~d}$ after maturity (Fig. 1). NM9335 bulb fresh weight increased $\approx 8 \%$ at $15 \mathrm{~d}$ after maturity, which may indicate that the harvest rating of $\approx 80 \%$ tops fallen was premature for this population (Fig. 1).

Percent dry weight of NM9335 bulbs was constant, and GS02 and GS04 percent dry weight increased before maturity (Fig. 1), which indicates that bulb percent dry weight before maturity did not indicate percent dry weight at maturity in the high-solids dehydrator onion cultivars. Lancaster and Kelly (1984) studied percent dry weight in bulbs of 'Southport White Globe' and 'Spartan Sleeper', with $\approx 13 \%$ bulb dry weight, and reported that percent dry weight before maturity accurately predicted percent dry weight at maturity, by testing the third inner scale. Their study was not replicated, and

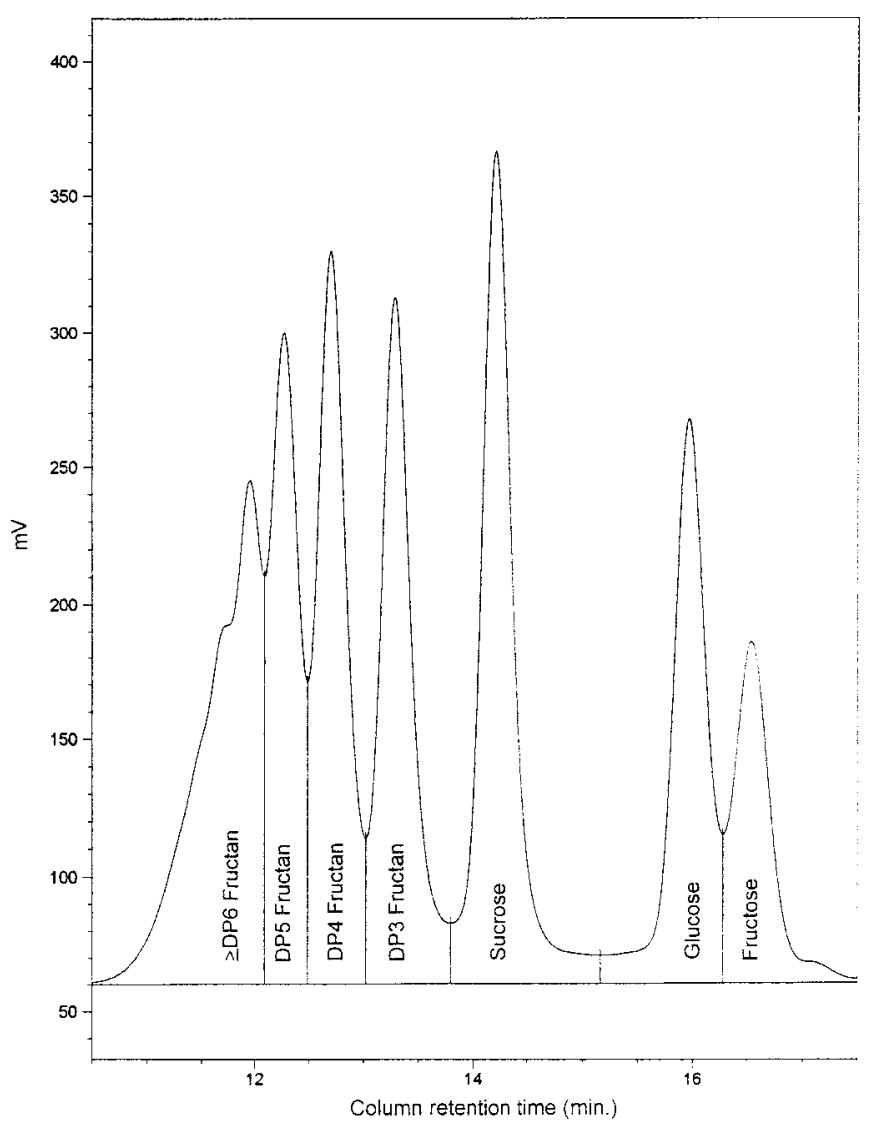

Fig. 2. High-performance liquid chromatogram of soluble carbohydrates for a 10bulb sample of dehydrator onion breeding population NM9335 at maturity in 1994. DP denotes the degree of polymerization of fructan polysaccharide. data were reported based on single bulb samples, so their results were more likely a reflection of variability for bulb percent dry weight within the study populations rather than an effect of bulb maturity on percent dry weight.

At maturity, bulbs of NM9335, GS02 and GS04 had $11.9 \% \pm$ $0.33 \%, 18.6 \% \pm 0.27 \%$ and $19.4 \% \pm 0.40 \%$ dry weight, respectively. Bulb percent dry weight decreased $0.5 \%$ to $1 \%$ at $30 \mathrm{~d}$ after maturity for each population(Fig. 1). Bulb percent dry weight losses could perhaps be due to carbohydrate respiration, balanced by increases in percent dry weight due to bulb desiccation.

ONION WATER SOLUBLE CARBOHYDRATES BEFORE AND AFTER MATURITY. Profiles of WSC were distinctly different between the intermediate-solids NM9335 breeding population (Fig. 2) and the high-solids GS04 commercial cultivar (Fig. 3). Differences between the higher DP fructans were not resolvable because of coelution at the same column retention time, which was indicated by chromatograms with an indistinct secondary peak preceding the main peak of the highest DP fructan (Figs. 2 and 3).

At each maturity, GSO4 had a much larger proportion of bulb dry weight in WSC, relative to NM9335, and most of the WSC was $\geq$ DP6 fructan (Figs. 4 and 5). Fructose, glucose and sucrose were relatively low in GS04, and were relatively high in NM9335, which concurs with results of Darbyshire and Henry (1979), who also studied WSC of intermediate- and high-solids onion populations. Fructose and sucrose levels were variable across all maturity dates in GS04 bulbs, whereas, glucose levels decreased approaching maturity, and then increased slightly after maturity (Fig. 4). Propor-

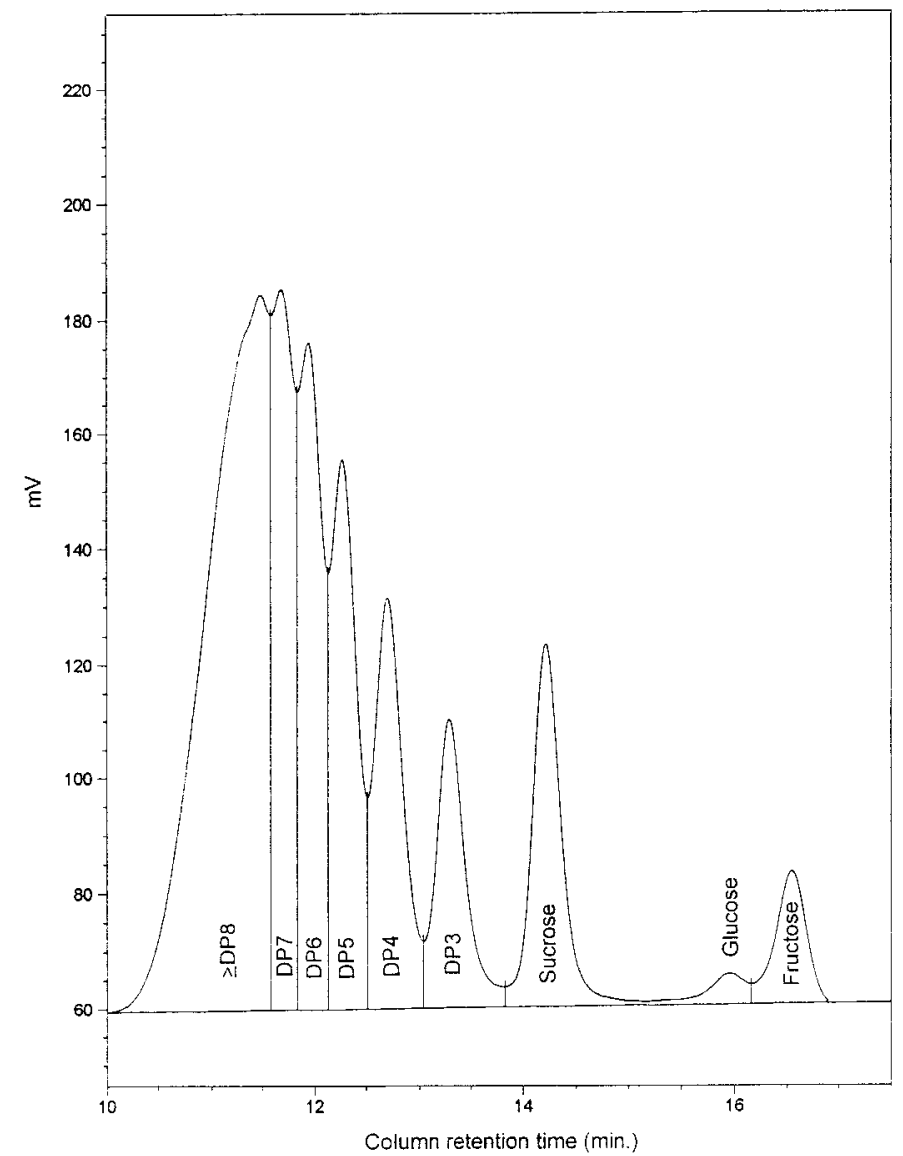

Fig. 3. High-performance liquid chromatogram of soluble carbohydrates for a 10bulb sample of commercial dehydrator onion cultivar GS04 at maturity in 1994 DP denotes the degree of polymerization of fructan polysaccharide. 


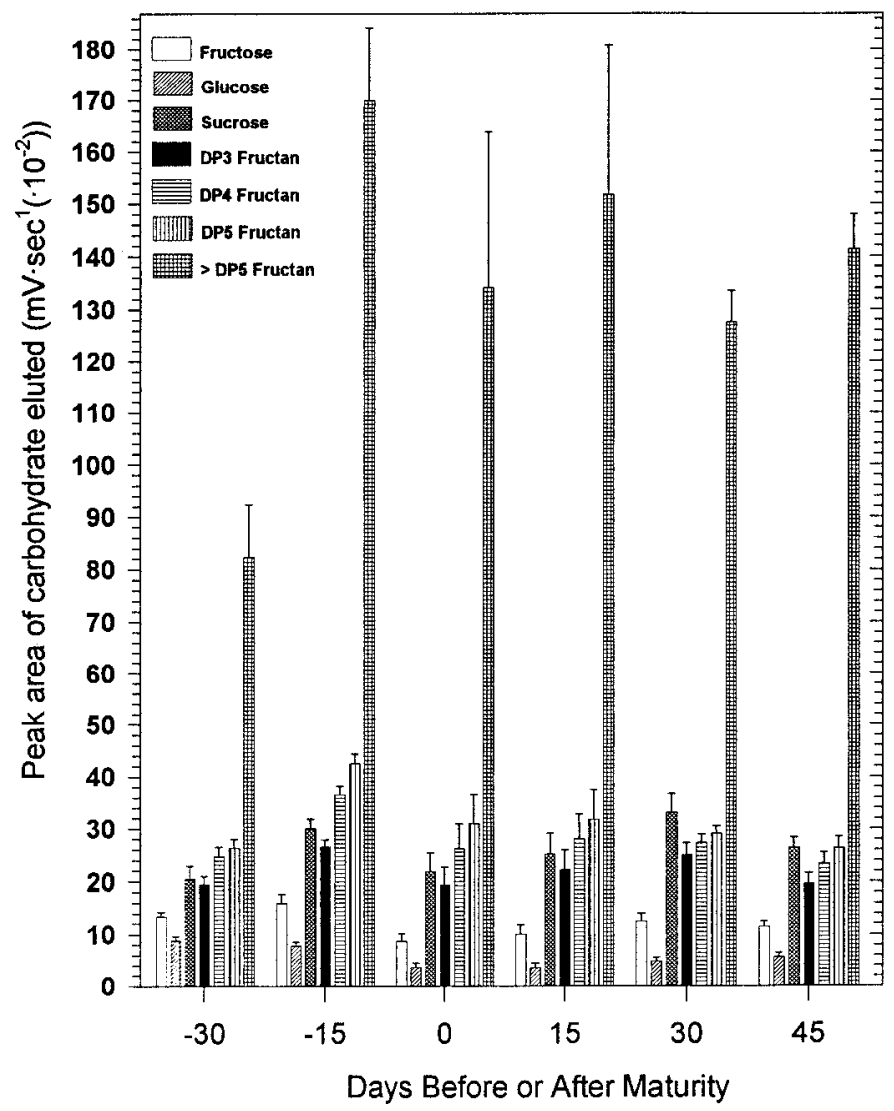

Fig. 4. Proportions of soluble carbohydrates from bulbs of commercial dehydrator onion cultivar GS04 before and after maturity, averaged over 1994 and 1995. Data for the 45 d postmaturity treatment is from 1994 only.

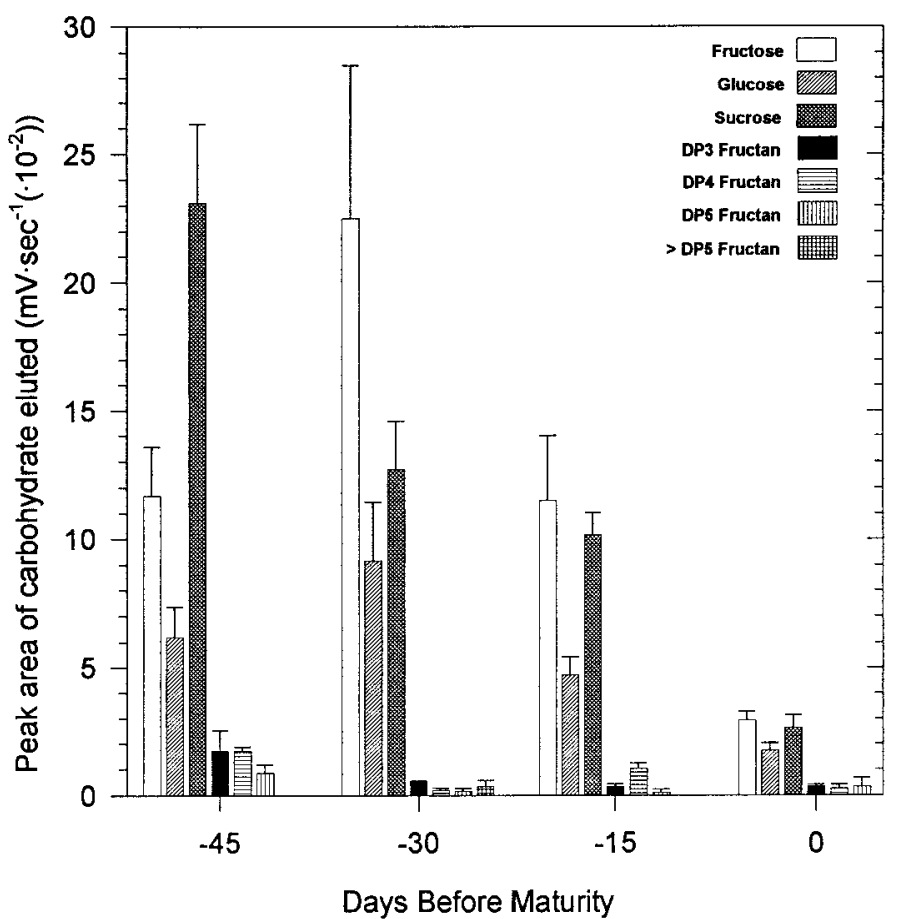

Fig. 6. Proportions of soluble carbohydrates from leaves of commercial dehydrator onion cultivar GS04 before maturity, averaged over 1994 and 1995. Data for the -45 d prematurity treatment is from 1994 only.

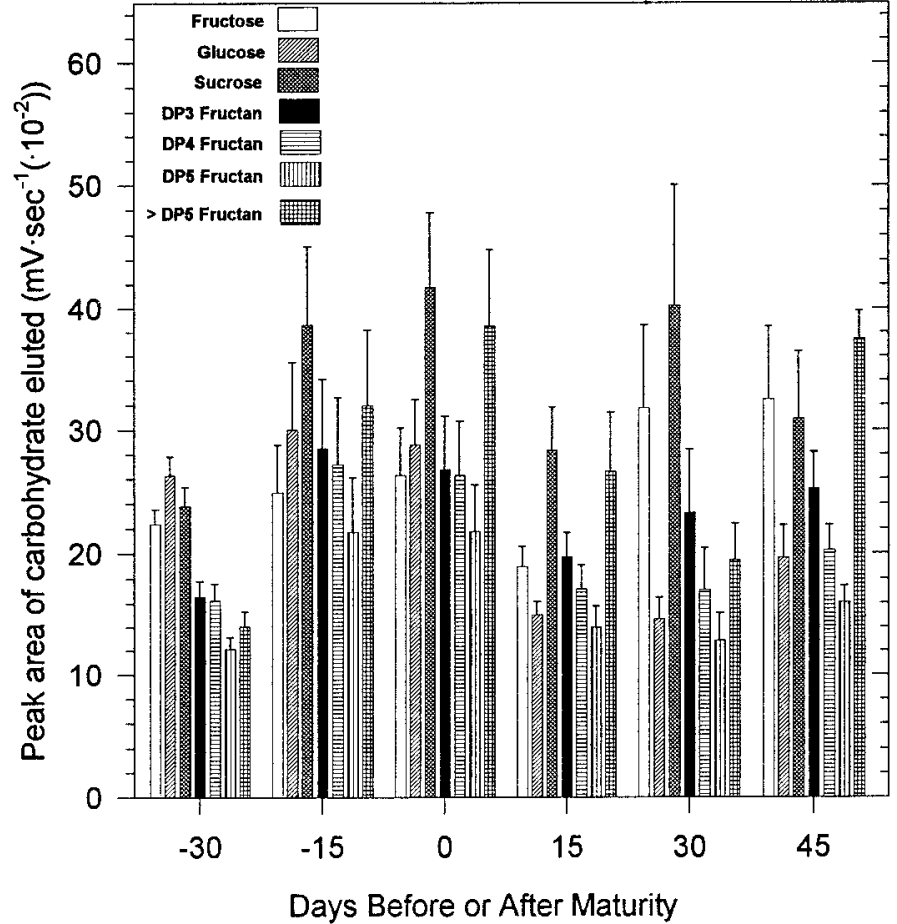

Fig. 5. Proportions of soluble carbohydrates from bulbs of dehydrator onion breeding line NM9335 before and after maturity, averaged over 1994 and 1995. Data for the 45 d postmaturity treatment is from 1994 only.

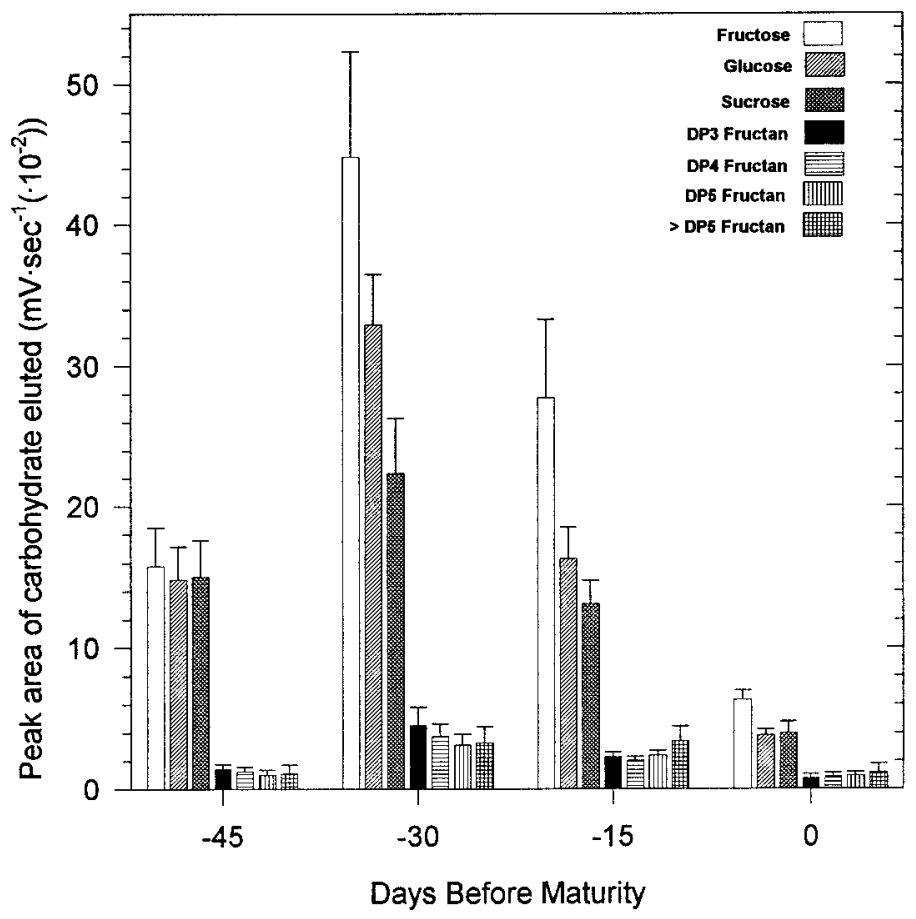

Fig. 7. Proportions of soluble carbohydrates from pseudostems of commercial dehydrator onion cultivar GS04 before maturity, averaged over 1994 and 1995. Data for the $-45 \mathrm{~d}$ prematurity treatment is from 1994 only. 
tions of DP3, DP4, and DP5 fructan were generally consistent before and after maturity, whereas most WSC accumulated as $\geq$ DP6 fructan before maturity in GS04 bulbs. Fructan $\geq$ DP6 was measured at various levels after maturity in GS04 bulbs (Fig. 4). Mean standard errors of $\geq$ DP6 fructan in GS04 bulbs were high. This may have been due to environmental variability, because laboratory replications were derived from replicated field plots. Also, sample variability would likely have been improved if the entire 10 bulb subsample from each replication had been ground to pass an 80 mesh screen.

Proportions of fructose, glucose and sucrose were variable in NM9335 bulbs across maturity treatments (Fig. 5). Fructan levels increased in order from DP3 to DP6 in GS04 bulbs (Fig. 4), but decreased in order from DP6 to DP4 in NM9335 (Fig. 5), before and after maturity. This indicates that GSO4 accumulated more high-DP fructan, and NM9335 more short-DP fructan. These differences in WSC profiles provide interesting contrasts for further research on fructan synthesis and carbohydrate biochemistry, especially for the enzyme fructose-fructosyltransferase (polymerase) that is reported to control the DP of fructan molecules (Cairns, 1993; Henry and Darbyshire, 1978, 1979). Darbyshire and Henry (1979) also reported that high-solids onion WSC was mostly in the form of higher DP fructan, and with relatively low amounts of glucose, fructose and sucrose.

Differences between populations for WSC profile lead to relevant questions for onion breeders. Breeding populations under development for dehydrator characteristics are often screened for bulb percent dry weight directly by dehydration, or indirectly by using a refractometer to test for soluble solids in onion juice (Dowker, 1990; Pike, 1986). Refractometer data can have up to a 0.99 correlation with dry weight (Sinclair, 1995), but do not reflect proportions of constituent WSC. Dehydrator onion cultivars with

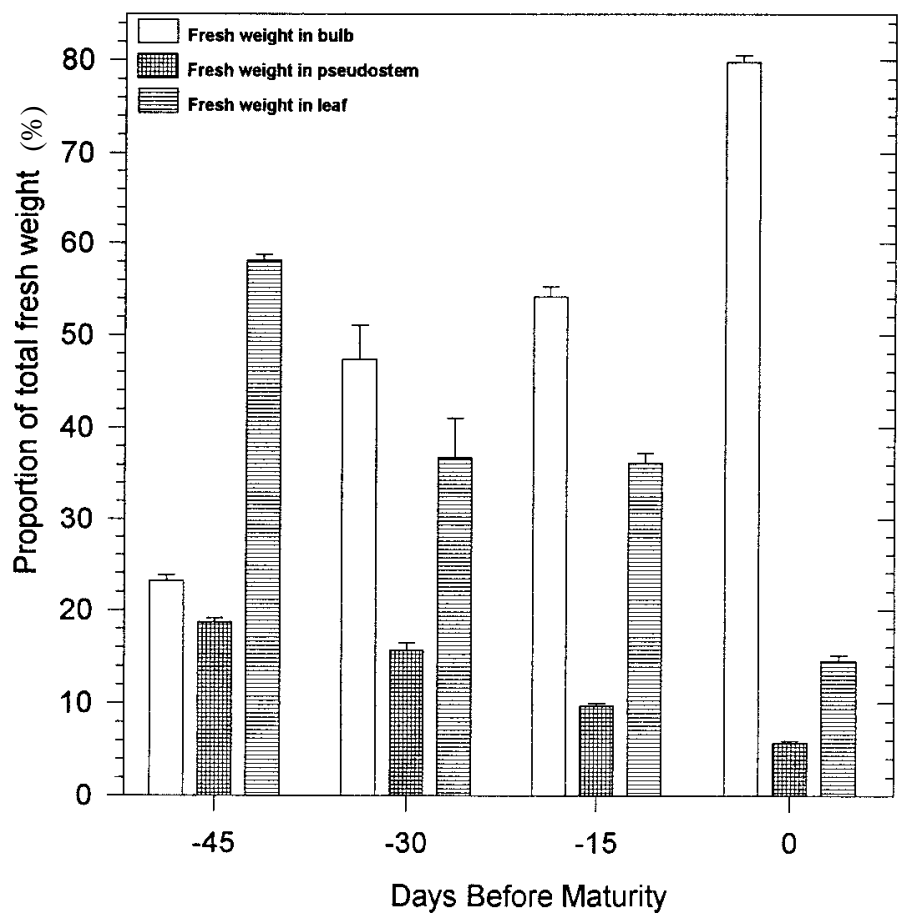

Fig. 8. Proportions of plant fresh weight in bulbs, pseudostems, and leaves of commercial dehydrator onion cultivar GS04 before maturity, averaged over 1994 and 1995. Data is expressed as percent of total plant weight. Data for the $-45 \mathrm{~d}$ prematurity treatment is from 1994 only. high bulb solids may possess better processing characteristics, such as whiter color after drying, better organoleptic properties, or better milling qualities, relative to onion populations with lower bulb solids, which also are relatively lower in fructan and higher in sucrose, fructose and glucose. Simple sugars (mono- and disaccharides) in onions may lead to greater browning, or caramelization reactions, during the dehydration process. In these studies GSO2 and GS04 bulbs with $\approx 18.5 \%$ to $19.5 \%$ solids dried with a whiter color than bulbs of the $\approx 12 \%$ solids, NM9335, under similar drying conditions, based on subjective observation. NM9335 bulbs were relatively low in fructan and high in the sugars, fructose, glucose and sucrose, compared to GS04 bulbs. Presently, there are no reports on how recurrent selection for bulb dry weight or SSC will affect WSC profiles, or if recurrent selection will increase fructan content, without a proportional increase in fructose, glucose and sucrose.

WATER SOLUBLE CARBOHYDRATE CHARACTERISTICS OF GS04 BULBS, LEAVES, AND PSEUDOSTEMS BEFORE MATURITY. Water soluble carbohydrate increased from the base to the top of GS04 plants before maturity, which agrees with the report of Darbyshire and Henry (1978). Very small amounts of DP3 to DP5 fructan were detected in GS04 pseudostems, and trace amounts were found in leaves before maturity (Figs. 6 and 7). Leaf and pseudostem WSC were mostly simple sugars, which decreased as the proportion of dry weight before maturity (Figs. 6 and 7). Pseudostem WSC increased from 45 to $30 \mathrm{~d}$ before maturity, and then declined from $30 \mathrm{~d}$ before maturity to maturity (Fig. 7). The study period coincided with the last six weeks of bulb development, as onion plants translocate photosynthetic carbon to bulbs before bulb summer dormancy.

Darbyshire and Steer (1990) also reported that levels of sugar in leaves, pseudostems, and bulbs increase with age until the final stages of bulb development. Darbyshire et al. (1979) reported that fructose levels in leaves and pseudostems were generally higher than glucose or sucrose, but diurnal fluctuation affected the amount

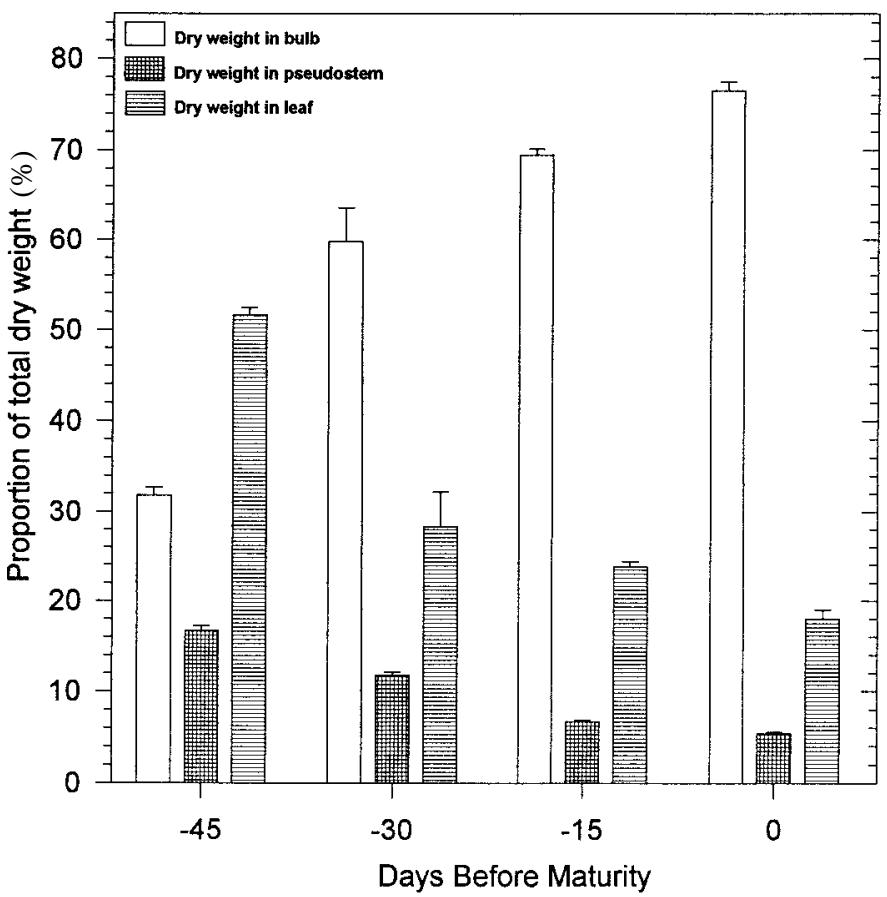

Fig. 9. Proportions of plant dry weight in bulbs, pseudostems, and leaves of commercial dehydrator onion cultivar GS04 before maturity, averaged over 1994 and 1995. Data is expressed as percent of total plant weight. Data for the $-45 \mathrm{~d}$ prematurity treatment is from 1994 only. 
and types of sugars in onion leaves and pseudostems. Several studies have shown that fructan accumulation in leaf bases of young plants coincides with initiation of bulbing in onions (Darbyshire and Henry, 1978; Henry and Darbyshire, 1978). Changes in WSC composition in leaves and pseudostems may coincide with the cessation of new leaf emergence, which denotes the end of vegetative growth and acceleration of active bulb enlargement in onions (Brewster, 1990).

WEIGHT PARTITIONING IN GS04 PLANTS BEFORE MATURITY. GS04 bulb weight increased, and pseudostem and leaf weight decreased before maturity (Figs. 8 and 9). The proportion of whole plant dry weight in bulbs increased from $31.8 \pm 0.01$ to $76.5 \pm 0.01 \%$ in the $45 \mathrm{~d}$ period before maturity, demonstrating that the GS04 dehydrator onion cultivar was very efficient at converting plant dry weight into net yield, which is commonly expressed as the crop harvest index.

\section{Conclusions}

The commercial dehydrator cultivars and the breeding population had distinctly different bulb weight and WSC characteristics. Bulb traits and WSC profiles of the commercial cultivars provide standards for progress in the breeding population. The HPLC method is useful to evaluate potential parents for a breeding program, to typify breeding populations, and to evaluate progress in selecting for WSC content. The method ideally would be improved to resolve differences between higher DP fructans, to reduce sample variability, and to develop fructan standards to quantify onion WSC.

\section{Literature Cited}

American Spice Trade Association. 1993. Proc. 5th Annu. Spice Tech. Forum. Amer. Spice Trade Assn., Englewood Cliffs, N.J.

Bailey, A.L. and J.N. Corgan. 1986. Growing onions in New Mexico. N.M. State Univ. Coop. Ext. Serv. Circ. 524.

Birth, G.S. and G.G. Dull. 1985. Nondestructive spectrophotometric determination of dry matter in onions. J. Amer. Soc. Hort. Sci. 110:297303.

Brewster, J.L. 1990. Physiology of crop growth and bulbing, p. 53-88. In: J.L. Brewster and H.D. Rabinowitch (eds.). Onions and allied crops. vol. 1. CRC Press, Boca Raton, Fla.

Cairns, A.J. 1993. Evidence for the de novo synthesis of fructan by enzymes from higher plants: a reappraisal of the SST/FFT model. New Phytol. 123:15-24.

Corgan, J.N. and N. Kedar. 1990. Onion cultivation in subtropical climates, p. 31-48. In: J.L. Brewster and H.D. Rabinowitch (eds.). Onions and allied crops. vol. 2. CRC Press, Boca Raton, Fla.
Darbyshire, B. and R.J. Henry. 1978. The distribution of fructan in onions. New Phytol. 81:29-34.

Darbyshire, B. and R.J. Henry. 1979. The association of fructan with high percentage dry weight in onion cultivars suitable for dehydrating. J. Sci. Food Agr. 30:1035-1038.

Darbyshire, B. and R.J. Henry. 1981. Differences in fructan content and synthesis in some Allium species. New Phytol. 87:249-256.

Darbyshire, B., R.J.Henry, F.M. Melhuish, and R.K Hewett. 1979. Diurnal variations in nonstructural carbohydrates, leaf extension, and leaf cavity carbon dioxide concentrations in Allium cepa L. J. Expt. Bot. 30:109115.

Darbyshire, B. and B.T. Steer. 1990. Carbohydrate biochemistry, p. 1-16. In: J.L. Brewster and H.D. Rabinowitch (eds.). Onions and allied crops. vol. 3. CRC Press, Boca Raton, Fla.

Dowker, B.D. 1990. Onion breeding, p. 215-232. In: J.L. Brewster and H.D. Rabinowitch (eds.). Onions and allied crops. vol. 1. CRC Press, Boca Raton, Fla.

Endleman, J. and T.G. Jefford. 1968. The mechanism of fructosan metabolism in higher plants as exemplified in Helianthus tuberosus. New Phytol. 67:517-531.

Fenwick, R.G. and A.B. Hanley. 1990. Processing of alliums: use in food manufacture, p. 73-91. In: J.L. Brewster and H.D. Rabinowitch (eds.). Onions and allied crops. vol. 3. CRC Press, Boca Raton, Fla.

Henry, R.J. and B. Darbyshire. 1978. The distribution of fructan metabolizing enzymes in the onion plant. Plant Sci. Lett. 14:155-158.

Henry, R.J. and B. Darbyshire. 1979. Sucrose:sucrose fructosyltransferase and fructan:fructan fructosyltransferase from Allium cepa. Phytochem. 19:1017-1020.

Kehr, A.E. 1952. Soluble solids and their determination in onions. Proc. Assn. S. Agr. Workers 49:110.

Lancaster, J.E. and K.E. Kelly. 1984. Dry matter percentage of leaf blades and scales during the growth of onion (Allium cepa $\mathrm{L}$ ). N.Z. J. Agr. Res. 27:83-87.

Mann, L.K. and B.J. Hoyle. 1945. Use of the refractometer for selecting onion bulbs high in dry matter for breeding. Proc. Amer. Soc. Hort. Sci. 46:285-292.

Nieuwhof, M., J.W. de Bruyn, and F. Garretsen. 1973. Methods to determine solidity and dry matter content of onions (Allium cepa L.). Euphytica 22:39-47.

Pike, L.M. 1986. Onion breeding, p. 357-394. In: M.J. Basset (ed.). Breeding vegetable crops. AVI Publ., Westport, Conn.

Scobell, H.D., K.M. Brobst and E.M. Steele. 1977. Automated liquid chromatographic system for analysis of carbohydrate mixtures. Cereal Chem. 54:905-917.

Sinclair, P.J., A.B. Blakeney, and E.W.R. Barlow. 1995. Relationships between bulb dry matter content, soluble solids concentration and nonstructural carbohydrate composition in the onion (Allium cepa). J. Sci. Food Agr. 69:203-209.

Suzuki, M. and J.A. Cutcliffe. 1989. Fructan in onion bulbs in relation to storage life. Can. J. Plant Sci. 69:1327-1333. 